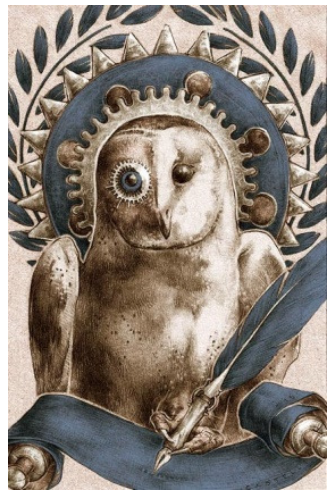

Intelligere, Revista de História Intelectual

vol. 3, no 2, out.2017

DOSSIÊ: sentido e relevância da História no mundo contemporâneo

\title{
Visibilidade e visualização ${ }^{1}$
}

\author{
André de Melo Araújo \\ Prof. Adjunto do Departamento de História da Universidade de Brasília \\ andaraujo@unb.br
}

Recebido em 04/02/2017. Aprovado em 31/03/2017.

Como citar este artigo: Araújo, André de M. "Visibilidade e visualização". Intelligere, Revista de História Intelectual, vol. 3, n², p. 47-53. 2017. Disponível em <http://revistas.usp.br/revistaintelligere>. Acesso em dd/mm/aaaa.

Resumo: Este artigo analisa o conceito de constituição estética do sentido histórico tal como apresentado na obra de Jörn Rüsen. Em um primeiro passo, identificam-se os pontos de contato do quadro teórico de Rüsen com o conceito de densidade icônica do sentido, desenvolvido pelo historiador da arte Max Imdahl. Em um segundo passo, os termos do debate anunciado por Rüsen são ampliados, uma vez que o atual desafio colocado pelas imagens não mais se limita à possibilidade de conferir visibilidade aos acontecimentos ou ao sentido históricos, mas se reconfigura ao considerar as estratégias por meio das quais os objetos da ciência e o pensamento científico são visualizados.

Palavras-chave: Jörn Rüsen; Imagem; Estética.

\section{Visibility and visualization}

\begin{abstract}
This article analyzes the aesthetic concept of historical sense as developed in Jörn Rüsen's work. In a first step, I identify the points of contact of Jörn Rüsen's theoretical framework with the concept of iconic density of sense, as developed by the art historian Max Imdahl. In a second step, the terms of the debate announced by Rüsen are broadened, since the current challenge posed by the images is no longer limited to the possibility of giving visibility to historical events or to the historical sense, but is reconfigured when considering the strategies through which the objects of science and the scientific thought itself are visualized.
\end{abstract}

Keywords: Jörn Rüsen; Image; Aesthetics.

$1 \mathrm{O}$ autor agradece à Fundação de Apoio à Pesquisa do Distrito Federal (FAPDF) e ao Conselho Nacional de Desenvolvimento Científico e Tecnológico (CNPq) pelo apoio para realização de uma pesquisa mais ampla sobre a informação visual no conhecimento histórico. Também agradeço a Arthur Alfaix Assis pelos comentários feitos à primeira versão deste artigo. 
I will define the epigraph roughly as a quotation placed en exergue [in the exergue], generally at the head of a work or a section of a work; literally, en exergue means off the work, which is going a little too far. Here the exergue is, rather, at the edge of the work, generally closest to the text - thus, following the dedication, if there is one. Hence the metonymy, so common nowadays, of exergue for 'epigraph' - a metonymy that does not seem to me very felicitous, for it confuses the thing with the place. ${ }^{2}$

Não são raros os trabalhos de Jörn Rüsen precedidos por uma epígrafe. As passagens localizadas acima do texto principal, en exergue, revelam predileções, embates e circunstâncias de vida relacionados à trajetória acadêmica do teórico da História alemão. Herder, Schiller e Gervinus fazem parte das predileções, Nietzsche dos embates, enquanto que ditos expressos cartões postais, ${ }^{3}$ assim como também respostas de alunos a questionários, ${ }^{4}$ pertencem às experiências elevadas ao canto superior direito de suas páginas escritas. Sem pretensões estatísticas definitivas, parece-me que as ideias mais recorrentes que figuram de forma destacada nos artigos de Rüsen são aquelas de Leopold von Ranke.

A recorrência tanto no corpo do texto quanto nas epígrafes de Rüsen ao pensamento de Ranke se justifica sobretudo pela necessidade de refutar a visão comum segundo a qual o caráter científico da História encontra-se em oposição às dimensões retórica e estética da historiografia. ${ }^{5}$ Em Ranke, o teórico alemão encontra apoio para afirmar que
A História se diferencia das demais ciências porque ela é, simultaneamente, uma arte. Ela é ciência na medida em que recolhe, descobre, analisa em profundidade; e arte na medida em que representa e torna a dar forma ao que é descoberto, ao que é apreendido. Outras ciências se contentam simplesmente em registrar o que é descoberto em si mesmo: a isso se soma, na História, a capacidade de recriação. ${ }^{6}$

O pensamento de Ranke reproduzido acima foi retomado em diversas ocasiões por Jörn Rüsen. Ao endossar a atitude mediadora expressa nessa passagem, Rüsen tem por objetivo definir a dimensão estética da historiografia de modo associado à capacidade de recriação daquilo que a pesquisa histórica recolhe, descobre e analisa. E é em função dessa mesma dimensão estética da historiografia que se pode identificar "um elemento de liberdade"7 nas práticas rigorosas da operação do conhecimento guiada pelo método científico.

\footnotetext{
${ }^{2}$ Gerard Genette, Paratexts: Thresholds of interpretation (Cambridge: Cambridge University Press, 1997), 144.

${ }^{3}$ Veja-se a epígrafe publicada em: Jörn Rüsen, "Die Zukunft der Vergangenheit". In: Zerbrechende Zeit: Über den Sinn der Geschichte (Köln/Weimar/Wien: Böhlau, 2001), 131.

${ }^{4}$ Esse é o caso da epígrafe publicada em: Jörn Rüsen, "Narrative Competence: The Ontogeny of Historical and Moral Consciousness". In: Jörn Rüsen, History: Narration - Interpretation - Orientation (New York/Oxford: Berghahn Books, 2005), 21.

${ }^{5}$ Sobre essa posição, consulte-se sobretudo: Jörn Rüsen, "Rhetoric and Aesthetics of History: Leopold von Ranke". In: Jörn Rüsen, History: Narration - Interpretation - Orientation (New York/Oxford: Berghahn Books, 2005), 41.

${ }^{6}$ Leopold von Ranke, "O conceito de história universal (1831) [Trad.: Sérgio da Mata]". In: A História Pensada. Teoria e método na historiografia europeia do século XIX, ed. Estevão de Rezende Martins (São Paulo: Contexto, 2010), 202.

7 Jörn Rüsen, "Rhetoric and Aesthetics of History: Leopold von Ranke". In: History: Narration - Interpretation Orientation (New York/Oxford: Berghahn Books, 2005), 50-54; Jörn Rüsen, Teoria da bistória: uma teoria da história como ciência (Curitiba: Ed. UFPR, 2015), 86.
} 
Da atitude mediadora presente em Ranke e reafirmada por Rüsen, derivam dois problemas fundamentais. Uma vez que a História é arte na medida em que representa aquilo que é analisado rigorosamente em termos científicos, conjugam-se, em primeiro lugar, os procedimentos do método com a responsabilidade ética da liberdade controlada das práticas representacionais. Esse primeiro problema, ainda que de importância destacada, será considerado apenas marginalmente neste artigo. $\mathrm{O}$ foco deste estudo incide preferencialmente sobre um segundo problema derivado da atitude mediadora proposta por Rüsen, a saber: o que atualiza o realismo peculiar ${ }^{8}$ que combina o elemento de liberdade da expressão artística com o rigor do procedimento científico no pensamento histórico? E em que medida a importância desse realismo peculiar se reconfigura frente ao desafio presente da constituição estética do sentido histórico? Para enfrentar esse problema, procurar-se-á identificar, na primeira parte deste artigo, os pontos de contato do trabalho teórico alemão com o conceito de densidade icônica do sentido, tal como defendido por seu colega na Universidade de Bochum e professor de História da Arte, Max Imdahl. Na segunda parte do artigo, os termos do debate anunciado por Rüsen são ampliados, uma vez que o atual desafio colocado pelas imagens não mais se limita à possibilidade de conferir visibilidade aos acontecimentos ou ao sentido histórico, mas se reconfigura ao considerar as estratégias por meio das quais os objetos da ciência e o pensamento científico são visualizados.

\section{Recomposição do problema: visibilidade}

A passagem reproduzida acima e extraída das preleções de Ranke sobre o conceito de história universal ganha destaque, como epígrafe, em pelo menos duas versões distintas de um texto de Jörn Rüsen sobre a visibilidade da História. ${ }^{9}$ Nesses textos, o teórico alemão sustenta a tese segundo a qual a articulação da consciência histórica humana tem uma dimensão estética. ${ }^{10}$ Ao desenvolver essa tese, Rüsen confere destaque ao caráter sensorial do processo de apreensão visual de vestígios, símbolos e imagens relacionados a situações históricas particulares. Nesse sentido, o caminho aberto por Rüsen é tranquilo. A experiência cotidiana daqueles que observam torres de concreto e aço serem erguidas ao lado de construções mais antigas configura um exemplo claro da percepção visual da diferença temporal. Atribuir sentido histórico, no entanto, a acontecimentos do passado cujo valor para o presente justifica, por exemplo, a preservação de construções mais antigas relacionadas a esses acontecimentos, é tarefa da historiografia.

O movimento de constituição do sentido histórico é impulsionado, para Jörn Rüsen, por carências de orientação do presente e resulta do esforço analítico que ganha forma com a capacidade de recriação daquilo que a pesquisa histórica recolhe, descobre e analisa. Assim, o sentido histórico é conformado discursivamente - característica esta que confere fôlego à visão comum segundo a qual as dimensões retórica e estética da historiografia se sobrepõem ao seu caráter científico. Ciente do perigo moral que a radicalização dessa proposta apresenta para a História, o teórico alemão procura explorar um segundo caminho menos tranquilo. Rüsen se propõe a investigar não apenas a dimensão estética da articulação da consciência histórica humana, mas - em uma inversão lógica radical - também a possibilidade de constituição

\footnotetext{
8 Jörn Rüsen, "Rhetoric and Aesthetics of History: Leopold von Ranke". In: History: Narration - Interpretation Orientation (New York/Oxford: Berghahn Books, 2005), 45: "It is important, therefore, to understand what Ranke meant by the 'third element', mediating between the 'conceptualizing' and the 'reproducing' forces of the mind. It is unfortunate that Ranke's explanation is not very clear. [...] Therefore, the question as to what constitutes the third element still remains open. In other words, what actualizes the peculiar historical realism combining art and science?" ${ }^{9}$ Jörn Rüsen, "The visibility of history: Bridging the gap between Historiography and the Fine Arts". In: Historein, 5 , 2005, 130-141; Jörn Rüsen, "Über die Sichtbarkeit der Geschichte”. In: Zerbrechende Zeit: Über den Sinn der Geschichte (Köln/Weimar/Wien: Böhlau, 2001), 107-129.

${ }^{10}$ Jörn Rüsen, "Über die Sichtbarkeit der Geschichte”, 107.
} 
estética do sentido histórico. "É possível ver a História?"11 - pergunta-se o autor. Trata-se de uma pergunta que não se satisfaz com uma resposta que aponta para os elementos figurativos presentes em pinturas históricas ou em monumentos. Nesses casos, a percepção sensorial da imagem apenas desperta a lembrança sobre alguma coisa, remete a um acontecimento do passado sem que seu significado histórico encontre necessariamente uma representação estética. $^{12}$ Ao abrir as portas desse segundo caminho investigativo, Rüsen buscou nova companhia.

No canto superior direito da página, Ranke não estava sozinho. Acompanham a atitude mediadora do historiador do século XIX as considerações estéticas de Friedrich Schiller. "No silêncio pudico de tua mente", diz Schiller, "educa a verdade vitoriosa, exterioriza-a na beleza, para que não apenas o pensamento a homenageie, mas para que também os sentidos apreendam, amorosos, a sua aparição."13 A proposta de Schiller é mais radical do que aquela presente na atitude mediadora de Ranke. Em Schiller, o pensamento não apenas homenageia num ato de liberdade controlada - aquilo que os sentidos apreendem; ele cede espaço para a verdade que pode ser apreendida sensorialmente. A elevação gráfica do pensamento de Schiller no texto de Rüsen serve, portanto, a um propósito claro: o teórico da História retoma o espírito presente na passagem romântica com o objetivo de testar as possibilidades e os limites da constituição estética do sentido histórico. Não é exatamente o problema da verdade que interessa agora a Rüsen - como foi o caso do autor das cartas dedicadas à educação estética do homem -, mas sim investigar em que medida a qualidade histórica de uma relação social pode ser percebida sensorial e, assim, esteticamente. ${ }^{14}$

A pergunta se torna ainda mais aguda ao refletirmos sobre um caso possível de percepção visual da diferença temporal, a saber: a destituição da função primária de peças de uso cotidiano expostas na vitrine de um museu. De acordo com o teórico da História alemão, aos restos materiais do passado pode-se atribuir sentido histórico apenas metaesteticamente. Ou seja, uma vez organizadas em um espaço museológico, são as legendas e o texto explicativo que acompanham as peças que a elas conferem sentido histórico. Partindo-se desse caso, pergunta-se: como se pode apreender estética - e não metaesteticamente - o arco narrativo do passado para o presente? Em outras palavras: é possível que o sentido histórico se constitua visualmente, para além, portanto, do ato discursivo?

Ao procurar investigar em que medida critérios de sentido podem ser genuinamente estéticos, Jörn Rüsen se aproxima dos estudos sobre a arte. Também no caso dessa aproximação, a ideia é superar tanto a perspectiva que enfrenta as obras de arte como documentos históricos e deixam de lado suas qualidades estéticas, quanto aquela que acentua o valor artístico dos objetos e considera as relações históricas apenas como um quadro a partir do qual elementos iconológicos e iconográficos podem ser tematizados. ${ }^{15} \mathrm{Na}$ busca por essa superação, Rüsen agradece a Max Imdahl por valiosas sugestões. ${ }^{16}$

Apoiando-se nas reflexões de seu colega na Universidade de Bochum entre as décadas de 1970 e 1980, Rüsen avalia o potencial de constituição estética do sentido histórico. Diferentemente, no entanto, do que ocorre com Schiller, ou mesmo ainda da perspectiva

\footnotetext{
${ }^{11}$ Ibid., 109: "Kann man Geschichte sehen?”

12 Ibid., 110.

${ }^{13}$ Friedrich Schiller, A educacão estética do homem: Numa série de cartas, trad., ed. Roberto Schwarz \& Márcio Suzuki (São Paulo: Iluminuras, 1995), Carta IX, 55. Texto original da epígrafe presente no artigo de Rüsen: "In der schammhaften Stille deines Gemüts erziehe ich die siegende Wahrheit, stelle sie aus dir heraus in der Schönheit, daß nicht bloß der Gedanke ihr huldige, sondern auch der Sinn ihre Erscheinung liebend ergreife." Apud: Jörn Rüsen, "Über die Sichtbarkeit der Geschichte", 107.

14 Jörn Rüsen, "Über die Sichtbarkeit der Geschichte". In: Zerbrechende Zeit: Über den Sinn der Geschichte (Köln/Weimar/Wien: Böhlau, 2001), 112.

${ }^{15}$ Ibid., 126-127.

${ }^{16}$ Ibid., 108.
} 
presente no debate filosófico contemporâneo fundamentada nas ideias de Martin Heidegger ou de Hans-Georg Gadamer, ${ }^{17}$ Rüsen se aproxima dos estudos de Imdahl para não perder de vista uma preocupação de ordem metodológica.

O método de interpretação de imagens proposto por Max Imdahl é chamado de icônico. Trata-se de uma proposta complementar à análise iconográfica e iconológica de Erwin Panofski que, por sua vez - de acordo com a crítica de Imdahl -, opera com uma concepção de imagem que se limita apenas a identificar, a reconhecer os objetos visuais. 18 "As evidências visuais que ultrapassam os elementos já conhecidos [previamente e] identificados pela visão ao se observar um objeto são deixadas de lado" por Panofski, segundo a perspectiva do historiador da arte da Universidade de Bochum. ${ }^{19}$ Frente a esse limite, Imdahl propõe uma síntese entre aquilo que se vê e aquilo que se reconhece por meio da visão: enquanto que para Panofski as "imagens são reservatórios e transformadores de sentido", para Imdahl elas são "geradoras de sentido". ${ }^{20}$ Rüsen se interessa, portanto, por um método de interpretação que considera "a pura força visual de uma imagem", força esta que "resiste e modula a referência textual"21 uma vez que também ela é capaz de gerar sentido.

Apesar de reconhecer a potencialidade do método proposto por Imdahl, o teórico da História encontra dificuldades para definir e categorizar o processo de constituição estética do sentido histórico. É certo que a definição de visibilidade do sentido histórico em Rüsen se associa à experiência da percepção sensória da diferença temporal, experiência esta cujo valor cognitivo - eis o desafio - abre-se à possibilidade de se deixar representar esteticamente. Todavia, essas rápidas reflexões sobre o tema não se encerram com um encaminhamento mais definido do problema que o teórico anuncia. Elas se encerram com um forte apelo: "Se não reconhecermos o desafio colocado pelas belas artes, fracassaremos." $22 \mathrm{O}$ desafio colocado para a reflexão teórica de Jörn Rüsen aponta para eficácia suficiente da forma artística no que diz respeito à visibilidade do sentido. E uma vez que esse é um desafio mais anunciado do que efetivamente encaminhado pelo autor alemão, é preciso agora ampliar os termos do debate e considerar o problema identificado por Rüsen não como um ponto de chegada, mas como um ponto de partida.

\section{Ampliação do problema: visualização}

Ao apresentar, nessa ordem, as epígrafes de Ranke e Schiller, Rüsen chama atenção para a postura mediadora entre arte e ciência defendida pelo autor do século XIX e, apenas em seguida, abre a possibilidade de que o sentido operado pela ciência histórica possa se constituir esteticamente. Todavia, a proposta de Rüsen talvez melhor se expresse no confronto analítico das epígrafes do que no desenvolvimento conceitual de sua obra. Trata-se, portanto, de um problema que permanece em aberto e para o qual não se encontra, nos textos do autor, uma

\footnotetext{
17 Tanto a teoria hermenêutica, quanto as reflexões estéticas de Martin Heidegger e Hans-Georg Gadamer têm um forte acento ontológico. Rüsen se afasta dessa perspectiva e critica, inclusive, a posição de Gadamer por deixar de lado, em seu estudo sobre a verdade hermenêutica, o problema do método. Cf. Jörn Rüsen, Teoria da história: uma teoria da bistória como ciência (Curitiba: Ed. UFPR, 2015), 61.

${ }^{18}$ Max Imdahl, Giotto - Arenafresken: Ikonographie - Ikonologie - Ikonik (München: Fink, 1988), 89.

${ }_{19}$ Max Imdahl, Giotto - Arenafresken: Ikonographie - Ikonologie - Ikonik, 90.

${ }^{20}$ Essa comparação precisa entre a proposta de Panofski e a síntese de Imdahl encontra-se, nesses termos, em: Felix Thürlemann, "Ikonographie, Ikonologie, Ikonik: Max Imdahl liest Erwin Panofsky". In: Bildtheorien: Anthropologische und kulturelle Grundlagen des Visualistic Turn, ed. Klaus Sachs-Hombach (Berlin: Suhrkamp, 2009), 233: "Für Erwin Panofsky sind die Bilder Speicher und Transformatoren von Bedeutung, für Max Imdahl sind sie Generatoren von Bedeutung."

${ }^{21}$ Vlad Ionescu, "What do you see? The phenomenological model of image analysis: Fiedler, Husserl, Imdahl", Image [\&] Narrative, [vol.] 15, 3 (2014): 108 (93-110)

22 Jörn Rüsen, "The visibility of history: Bridging the gap between Historiography and the Fine Arts", Historein, 5 (2005): 140 (130-141): "If we do not recognize the challenge posed by fine art, we will fail."
} 
resposta acabada. Desse modo, não resta outra alternativa senão descolarmos da proposta inicial de Rüsen e partirmos agora para averiguar em que renovados termos o debate entre ciência e arte resulta, contemporaneamente, em uma fértil reflexão sobre a visibilidade e sobre os mecanismos de visualização tanto dos objetos do conhecimento, quanto do pensamento científico.

Na obra Picturing Science, Producing Art, ${ }^{23}$ Peter Galison apresenta as imagens utilizadas pela ciência ao longo dos séculos de forma associada a um problema de ordem epistemológica. O debate, já previamente anunciado em outro estudo escrito em conjunto com Lorraine Daston $^{24}$ e posteriomente ampliado na obra Objectivity, ${ }^{25}$ procura refletir sobre o modo como o objeto da ciência ou o resultado das investigações científicas se tornam visíveis. As primeiras estratégias pictóricas estudadas por Daston e Galison encontram-se atreladas a uma série de práticas que orbitavam em torno da figura do gênio. Em nome de uma genialidade de aspirações universais, corrigiam-se e validavam-se tanto os traços que davam contorno, quanto os pinceis que emprestavam as cores às representações visuais das manifestações da natureza. Desvios imputados ao desenvolvimento descontrolado de um exemplar da natureza precisavam ser retocados para se chegar à representação universal e perfeita de uma espécie. ${ }^{26}$ Ora, esse tipo de interferência é estética no sentido pré-kantiano do termo, ou seja: trata-de de um aperfeiçoamento da realidade, de uma interferência necessária do artista com o objetivo de tornar as coisas mais claramente perceptíveis. ${ }^{27}$ No entanto, o modo de representação visual dos objetos da ciência muda na década de 1830, de acordo com a tese de Daston e Galison. No lugar do gênio transcendental que corrige a natureza ao idealizá-la, entram em cena uma série de "instrumentalidades que minimizaram a intervenção [...] e bloquearam a licença artística." 28 objetivo dessa estratégia passa a ser registrar mecanicamente os objetos. "A automaticidade soldou a imagem ao objeto, até que eles se tornassem uma única coisa; semelhança tornou-se identidade." 29

Até aqui, o caminho percorrido por Galison e Daston aponta para diferentes virtudes epistêmicas por meio das quais se operam estratégias representacionais pictóricas igualmente diversas. Trata-se de estratégias que ora combinam elementos de liberdade da expressão artística do gênio, ora excluem a possibilidade de interferência subjetiva do produtor do conhecimento. Em outros termos e com outra dimensão de análise, chega-se à conclusão que diferentes vistudes epistêmicas atualizam as estratégias representacionais peculiares que combinam o elemento de liberdade ou o velamento intencional da expressão artística com o rigor do procedimento científico. $\mathrm{O}$ argumento avança ao apresentar uma terceira virtude epistêmica, consolidada no século XX, à qual se associam as "imagens interpretadas" (interpreted images). Trata-se de imagens que não precisam ser homomórficas; ou seja, imagens que "não precisam corresponder, na forma, a algo que foi visto". ${ }^{30}$ Aqui, "um olho treinado consegue reconhecer padrões onde o iniciante não consegue ver nada", 31 de tal modo que a subjetividade volta a ser um elemento importante de classificação e conhecimento das propriedades dos objetos da ciência.

23 Picturing Science, Producing Art, eds. Caroline A. Jones e Peter Galison (New York/London: Routledge, 1998).

${ }^{24}$ Veja-se, por exemplo: Lorraine Daston e Peter Galison, “The Image of Objectivity”, Representations, 40 (1992), 81128.

${ }^{25}$ Lorraine Daston e Peter Galison, Objectivity (New York: Zone Books, 2007).

${ }^{26}$ Peter Galison, "Judgement against Objectivity". In: Picturing Science, Producing Art, eds. Caroline A. Jones e Peter Galison (New York/London: Routledge, 1998), 328.

${ }^{27}$ James Elkins, The Domain of Images (Ithaca/London: Cornell University Press, 1999), 11.

${ }_{28}$ Peter Galison, "Judgement against Objectivity”, 328.

${ }^{29}$ Ibid., 333.

${ }^{30}$ Peter Galison, “Judgement against Objectivity". In: Picturing Science, Producing Art, eds. Caroline A. Jones e Peter

Galison (New York/London: Routledge, 1998), 347.

${ }^{31}$ Peter Galison, "Judgement against Objectivity", 337. 
Resulta da organização cronológica dos modos de figuração das imagens da ciência que tanto para a representação guiada pela figura do gênio, quanto para aquela que procura uma forma de registro mecânico do objeto científico sem a interferência do sujeito que conhece, "o prefixo $r$ - é essencial." 32 Nesses dois casos, tem-se imagens que se esforçam para representar algo que pode ser apreendido pela visão, algo que tem um correspondente visível na natureza. Esse modo de representação figurativa apóia-se na ideia segundo a qual “o artista 'imita' a 'forma exterior' do objeto que está à sua frente, e o espectador, por seu turno, reconhece por essa ‘forma' o ‘assunto' da obra de arte." ${ }_{33}$ O corolário simplista e falacioso dessa concepção tradicional de representação como cópia é que toda imagem se refere "necessariamente a algo exterior a ela". ${ }^{34}$ Essa era a liga com a qual a objetividade mecânica soldara a imagem ao objeto.

O ponto é que a ciência contemporânea opera, inclusive, com imagens que não são homomórficas, de tal modo que elas menos representam e mais apresentam ${ }^{35}$ os objetos e as teorias da ciência. Os objetos apresentados são criados, não recolhidos, descobertos, uma vez que as imagens científicas passaram a ter uma força criacional, ${ }^{36}$ uma força geradora. Nesse sentido, ao se investigar o potencial cognitivo que se pode atribuir às propriedades das imagens, renova-se, em termos mais ampliados, o interesse em verificar como se configuram, esteticamente, "substitutos não-proposicionais de argumentos racionais". 37

\footnotetext{
${ }^{32}$ Lorraine Daston \& Peter Galison, Objectivity (New York: Zone Books, 2007), 382.

${ }^{33}$ E. H. Gombrich, "Meditações sobre um Cavalinho de Pau ou as Raízes da Forma Artística [1951]". In: Meditações sobre um Cavalinho de Pau e Outros Ensaios sobre a Teoria da Arte (São Paulo: EDUSP, 1999), 1.

${ }^{34}$ E. H. Gombrich, "Meditações sobre um Cavalinho de Pau ou as Raízes da Forma Artística [1951]". In: Meditações sobre um Cavalinho de Pau e Outros Ensaios sobre a Teoria da Arte (São Paulo: EDUSP, 1999), 2.

${ }^{35}$ Lorraine Daston \& Peter Galison, Objectivity (New York: Zone Books, 2007), 383.

${ }^{36}$ Lorraine Daston \& Peter Galison, Objectivity (New York: Zone Books, 2007), 415.

${ }^{37}$ James Elkins, The Domain of Images (Ithaca/London: Cornell University Press, 1999), 33.
} 